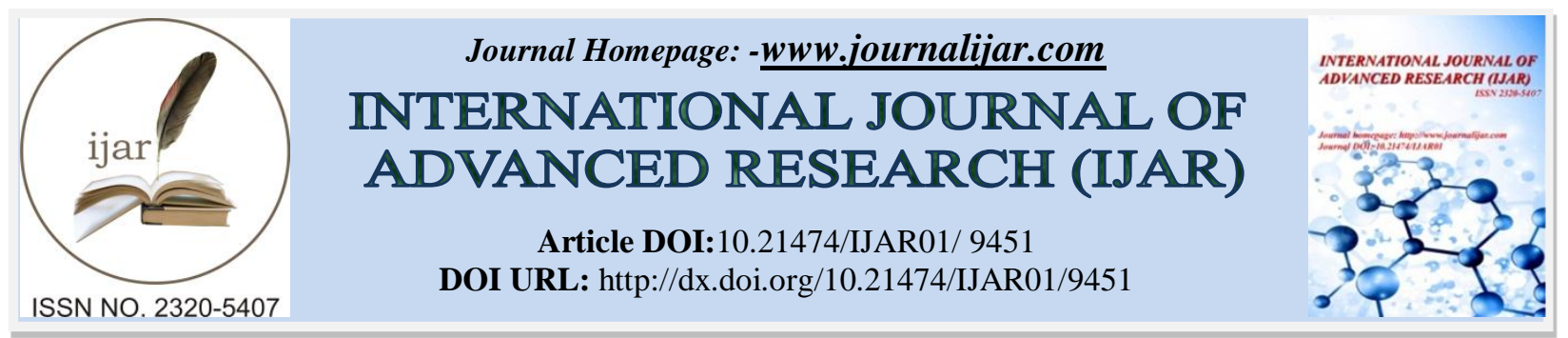

RESEARCH ARTICLE

\title{
THE ROLE OF ASSESSMENTS TO DEVELOP L2 SPEAKING: A COMPARATIVE STUDY BETWEEN THE YOUNG LEARNERS OF BANGLA AND ENGLISH MEDIUM EDUCATION SYSTEMS IN BANGLADESH.
}

Md. Zahangir Alam And Farhana Binte Mizan.

\section{Manuscript Info}

Manuscript History

Received: 24 May 2019

Final Accepted: 26 June 2019

Published: July 2019

Key words:-

BM (Bangla Medium), EM (English Medium), Assessment, Formative Assessment, Summative Assessment, Importance of Assessment.

\begin{abstract}
Assessment, the most fundamental and traditional way to make decision on learners' potential, provides an undeniable contribution in the field of second language teaching and learning. This study aims at finding out any relevant impact of assessments in improving the level of speaking competence of EM and BM students. To analyze this hypothesis, a survey was conducted as an instrument for obtaining data from students of Bangla Medium and English Medium schools. The findings of this paper contradict the popular beliefs about the curriculum which Bangla Medium Schools follow. Students feel assessment has significant role in their L2 speaking performance albeit they aren't evaluated on regular basis. Most surprisingly, any sort of achievement in ESL speaking doesn't affect learners' academic life. A very contrastive figure is observed in English Medium School where learners' performance in L2 speaking is closely linked to their academic life until grade 7. In EM schools, teachers evaluate students' speaking and record their performance on regular basis which keep them focused and motivated to improve L2 speaking competence though students aren't much aware about the assessment criteria. Finally, the study ends with the decision that ensuring practice of different assessments is the most affecting factor for the development and hindrance of L2 speaking fluency in EMS and BMS respectively.
\end{abstract}

Copy Right, IJAR, 2019,. All rights reserved.

\section{Introduction:-}

Assessment is an idespensible way of evaluating the students' achievement, finding their strengths and weaknesses and accelerating the learning. According to the dictionary of Cambridge 'Assessment' refers to the act of judging or deciding the amount, value, quality, or importance of something, or the judgment or decision that is made. But in language, assessment is referred as a way to measure how much students have learned up to a particular point in time. Or it can be said that assessment is "a systematic process for gathering data about student's achievement". It is an essential component of teaching (Dhindsa, Omar \& Waldrip, 2007) often called "assessment of learning".

In case of testing language skills, speaking requires more attention and diplomacy than that of rest of the skills. It is found to be difficult to assess due to its nature (Harries, 1969). Therefore it needs to be evaluated and developed properly to ensure a quality education as much as a mirror needs to be clear for clear reflection. Because how correctly people speak their language is an indication of their education system. Assessment is how the ability,

Corresponding Author:-Md. Zahangir Alam. 
performance and needs of the students can be identified and valued on the whole. It plays a key role in developing learners' oral ability and improving their capacity to learn. The use of oral ability motivates students to practice and improve their English speaking skill (Huang 2012; Huxham et al 2012; \& Lee, 2007)..

Assessment is an activity that engages both students and teachers in judgment about the quality of student's achievement or performance and inferences about the learning that has taken place (Boud \& Falchikov, 2006). Second language assessment is done either to gauge a participant's actual level of competence or to assess language development over a period of time (Alam, 2012; Bruton, 2009). Assessment is very important for the development of quality education (Black \& William, 1998). It has a significant impact on L2 learner's oral development. The use of oral assessment motivates students to practice and improve their English speaking skills (Huang, 2012; Huxham et al 2012; Lee, 2007)

In Bangladesh BM schools follow National Curriculum \& Textbook Board (NCTB) curriculum which includes summative (annual exams) and high stake (board exams) tests to fix the ladder of success of any students. L2 speaking is given much importance in the NCTB curriculum, the textbooks of all classes recommend speaking as the integral part, but surprisingly this is totally avoided in the high stake tests such as in SSC and HSC board exams. Under this circumstance, both teachers and students of BM feel reluctant to put their outmost dedication to deal with the challenges encountered while teaching and learning second language speaking. Students often believe that if they fail in L2 speaking during their early stage, it won't make any difference in their academic progress. As a result, the learners find no motivation and reasons to invest time in order to improve L2 speaking.

On the other hand, EM curriculum includes formative assessment (day to day, week to week or twice in a month) to evaluate the performance of learners. In English medium schools, learners are often assessed for their speaking. To ensure learning of the students in English medium education system, learners are assessed on their pronunciation, fluency, accuracy and most importantly comprehension.

Therefore, it's hypothesized that inclusion of similar assessments like English medium education system helps Bangla medium learners improve their L2 speaking. In that connection, this study shows that evaluation of students' performance matters for improving second language speaking. Also, the study recommends the ways how to include assessment in L2 speaking class.

\section{Conceptualizing Assessments in the field of Language Teaching Different types of assessments:}

A language teacher may accelerate learning procedure by assessing the performance of the students inside and outside the classroom. This can be done through variety of ways -formal assessment (evaluating learners by their academic performance) and informal assessment(assessing through extracurricular activities). On the basis of performance assessment is classified into two types-(a) Formative Assessment and (b) Summative Assessment. According to Gattullo (2000) formative assessment has three phases -(a)an ongoing multiphase process that is carried out on a daily basis through teacher-pupil interaction (b)it provides feedback for immediate action and (c) it aims at modifying teaching activities in order to improve learning process and result.

On the contrary Summative Assessment is used at the end of the term, semester or year, in order to measure what has been achieved both by groups and by individuals (Hughes, 1989). However, on the basis of curriculum there are two different testing systems - (a) High Stake testing and (b) Low Stake testing. "High stake testing is anything used to make important decisions about students, educators, schools or districts and is most commonly for the purpose of liability to ensure that students are enrolled in effective schools and is being taught by effective teachers (Partnership, 2014, p.1)".

The test which measures the academic achievement and identifies the learning problems after a particular time is referred to as low stake testing. But it does have a little impact on the learners' course grade. All these different assessments should be incorporated and implemented properly as they will facilitate an effective learning and teaching of L2 speaking.

\section{Impact of assessment:}

Strong impact of assessment on the language learning process has been noted by a large number of researchers like (Crooks, 1988; Heywood 1989; Nebble \& Jaeger, 1983).It helps the students to have integrated skills and exhibit 
their communicative abilities in realistic situation. Assessment does have a powerful impact on the learners which Hughes (1989) referred to as Backwash. This effect can be both positive and negative as it can motivate and demoralize learners at a time. "If the test content and testing techniques are at variance with the objectives of the course there is likely to be harmful backwash. An instance of this would be where students are following an English course that is meant to train them in the language skills necessary for university study in an English speaking country, but where the language test that they have to take in order to be admitted to a university does not test those skills directly" (Hughes, 1989). For this reason it is suggested that "If you want to encourage oral ability, then test oral ability (Hughes, 1989). The language teachers should carry a positive mind and should have a professional point of view so that learners can learn properly. However, the term 'impact' as it is used in educational measurement, is not limited to the effect of assessment on learning and teaching but extends to the way in which assessment affects society as a whole.

\section{Assessment in Bangladesh:}

In Bangladesh the system of assessment has always been guided by the curriculum though the system only covered the learners' ability of memorization and comprehension skills. In most of the Bangla medium schools students are evaluated only by summative assessments where their writing skills are emphasized." Students memorize answers and reproduce them in the exam and when they are asked to write a few sentences as their own they feel helpless. There has been no direct test of the skills except for reading and writing" (Barman; Sultana \& Lal, 2006).It has a long lasting negative impact on the learners. If assessment is limited to the written exams then students will only learn how to write (Ahmad, 2011; Akiyama, 2003; Ali et al, 2012).

\section{Challenges of implementing assessments:}

There are many challenges in the assessment of oral skills in a second language including: defining language proficiency, avoiding cultural biases and attaining validity (Sanchez, 2006). There is no scope for oral test in the classroom due to limited time and huge amount of students. It is hard to assess a number of students within a short time because the examiner is put under pressure (Heaton, 1989). Teachers are either reluctant to test oral ability or lack oral confidence in the validity of these assessments (Knight, 1992).Moreover the lack of public trust on oral examination makes the situation more complex (Bashir ,2011). Social and economic condition also affects implementing integrated assessment systems. Thus, in order to make students competent in L2 speaking, their evaluation should properly be carried out. Like other tests spoken tests need to ensure seven test qualities namely: reliability, validity, authenticity, inter-activeness, impact, practicality and absence of bias (Akiyama, 2003; Bilal et al, 2013; Lee2007).

The following questions have guided the current study's data collection and analysis:

1. To what extent curriculum of EMS and BMS education systems is effective to improve L2 speaking?

2. How does evaluation motivate learners from both systems to use L2 outside the classroom in real or realistic situation?

3. What are the major problems of materializing an inclusive assessment system in BMS curriculum?

\section{Methodology:-}

This exploratory type of study embarks on primary data and delves into finding the role of assessment in taking lead in L2 speaking skill. Quantitative approach was employed in the process of data collection.

\section{Participants}

A total of 60 learners were surveyed from Bangla and English Medium education system where there were 30 for each medium. In both education medium, learners were from grade 7 because in English medium schools, students' oral fluency is evaluated until grade 7.

\section{Context}

The sampling groups were selected purposefully from B.O.F Cantonment Public School and International Turkish Hope School for Bangla and English Medium education system respectively. B.O.F Cantonment Public School is run by Bangladesh Army authority and this institution has track record of good results. They focus on NCTB curriculum and under this curriculum students can pass or make very good results without focusing on L2 speaking. L2 is merely a neglected skill in the entire NCTB curriculum. In International Turkish Hope School, an English Medium School, learners are compelled using L2 speaking and assessed very often the abovementioned skill. To 
add more, any sort of performance in L2 speaking affects heavily students' academic life until class 7 . After 7 grades, this school guides their students for $\mathrm{O}$ level subject choice and no more assessment is done on speaking.

\section{Data Collection Instruments}

A research instrument in the form of survey questionnaire consisting nearly 09 questions (App-01) was used to collect data from the participants. Most of the survey questions are MCQ type beside few Order of Frequency type questions. The researchers explained all the questions to ease the understanding of the participants before distributing the questionnaire over to the learners (MS office-2010 was used to formulate the data on graphs).

\section{Results:-}

This section shows the results collected from the participants of the study. The tabulation sheet and the graphs are in appendix 02 and 03 respectively.

\section{Q-1: How many times is your $\mathrm{L} 2$ speaking assessed in a year?}

From the first dimension it is evident that most of the Bangla Medium students are not provided with ample amount of speaking assessments while a large number of English medium students get enough scope of evaluation. Nearly $60 \%$ students feel have expressed that their speaking skill is assessed twice in a year meanwhile over $70 \%$ learners from English Medium schools have said the skill is assessed quarterly.

\section{Q-2: Which of the following oral tests are you given?}

In English Medium School, 50\% of the students were weekly assessed with short test and nearly 30\% once in a month with a big test. However, in Bangla Medium Schools 70\% of the students are given big test once or twice in a year to evaluate their performance.

\section{Q-3: Which technique is applied to identify the ability of learners of using vocabulary?}

This dimension caters what sort of activity is assigned or technique applied to the learners to judge their ability to use L2 language vocabulary in speaking. In case of EM, the figure shows, $60 \%$ of the participants of English medium school opted "making sentence with new words" is applied to identify their ability of using vocabulary while $24 \%$ decided on "making a story with new words". Another $13 \%$ participants supported "telling synonym of each new word". Only $3 \%$ expressed that they were assessed given the ability to memorizing and using vocabulary.

On the other hand, very opposite trend is observed in Bangle medium schools, over $70 \%$ students were graded to detect their success in using vocabulary based on their ability of "telling synonym of each new word". Gradually $13 \%$ and $10 \%$ of them hold up "memorization" and "making sentence with new words" respectively. Students were rarely assigned any writing task to notice their excellence in using vocabulary.

\section{Q-4: Which specific area of $\mathrm{L} 2$ speaking skill is frequently focused in $\mathrm{L} 2$ classroom?}

Overall, in EM schools fluency and pronunciation are the focused areas in the process of learning L2 speaking. In comparison, in BMS accuracy makes the largest significance while accent and pronunciation are the least significant part which is not focused in L2 classroom.

About 50\% EM students have given their consent on "fluency" while the amount of BM students in this regard is followed by a slight decrease at $43 \%$.In BMS accuracy made up $17 \%$ but this figure rose to $57 \%$ for EMS. In connection to the importance on accuracy, it was $17 \%$ for EMs students which experienced more than threefold increase and climbed at 57\% BMS. But "pronunciation" and "accent "accounted for $33 \%$ which is followed by a dramatic decrease in 0\% in BMS. But in both of EMS \& BMS accent remained static which is 0\% and it is not highlighted at all. Moreover the percentage of "fluency" in EMS which is comprised of a greater 50\% fell to $43 \%$ in BMS.

\section{How far has evaluation raised a comprehensive impact on your L2 Speaking?}

To consider the impact of assessment in students' learning process, autonomously $40 \%$ students of EMs casted their opinions as it has significant role in their learning process and $33 \%$ expressed it carries medium level of impact. Surprisingly, $84 \%$ BM students have expressed that evaluation has always had a remarkable impact on their L2 speaking, albeit they weren't given or assessed regularly. 


\section{How does assessment help?}

To put the aid of assessment on high, $54 \%$ of English medium students pointed out it assists "to become more fluent speaker" and $23 \%$ of them said in case of extending vocabulary it is important. Another $20 \%$ of students feel it improves English test score.

The trend for BM students is quite surprising, $60 \%$ students supported assessment needs to be included in the curriculum "to become more fluent" at the same time $34 \%$ believed it aids "to expand vocabulary". An insignificant percent $6 \%$ of students expressed this has any value "to improve pronunciation".

\section{Is improvement of a real or realistic communication in L2 impossible without integrating assessment in learning process? \\ To defend the need of the including assessment in the curriculum, a very thick figure which are $90 \%$ and $87 \%$ students from EM and BM schools respectively agreed that without it they can't advance learning growth.}

\section{Does your instructor give any sudden test for assessing L2 speaking?}

It is seen that a large number of EMS students are sometimes provided with sudden test though most of the BM students are not facilitated with same sort of test. In EMs, teachers evaluate their 57\% students with sudden test whereas the figure saw a dramatic decrease at 30\% for the students of BMs. In EMS 6\% students are always provided sudden speaking test while, the ratio of the students in BMS declined exponentially in $0 \%$. About $27 \%$ EMS students give their consent on "often" but the agreement of BMs students in this regard increased moderately by $10 \%$.Moreover, only $10 \%$ EMS students are not judged by sudden test. In contrast there has been a sharp increase in the number of BMS students who don’t get this environment. It is speedily increased at $67 \%$.

\section{Do you get immediate feedback from your teacher?}

In case of teachers' feedback, 40\% EM students received immediate repercussion from their teachers after their performance in terms of using ESL speaking. In contrast, in BMS the number of students getting backwash deteriorate ceaselessly. About 30\% students have given their consent on "sometimes" \& "often", which tediously dropped in 27\% and 23\% respectively for BMS. Significantly none of the English Medium students have chosen "never" while the number of students in BMS increased considerably in $27 \%$.

\section{Findings and Discussions:-}

The result of this study reveals the picture of language assessment system of Bangla and English Medium School in Bangladesh and to compare between them. By analyzing data it is found that most of the BMS are still lagging far behind than EMS regarding their system of assessment.

1. Unfortunately it is seen in BMS that there is no proper arrangement for judging students' speaking fluency though this skill is put into the NCTB curriculum. In spite of focusing all skills of the language, only the productive skills (reading and writing) are emphasized in Bangla Medium schools. Though test on listening and speaking are included in the curriculum, it is not applied for evaluating the students. Avery limited number of Bangla Medium students are privileged with speaking test once or twice in a year. As there is no assessment for speaking ability and students do not get any mark for it, they have no more enthusiasm in developing speaking skills. In contrast, in EMS there is a wider scope of evaluating students' oral ability. Thus, they are assessed at least once in four months in one school year that helps them to stay focused in improving L2 speaking.

2. The participants also report that -while performing in the classroom they prefer producing grammatically correct sentences. And attention is not paid on fluency. As a result, learners are always haunted by the fear of making mistakes while presenting answers in the classroom. They try to learn language but conscious way, not the subconscious way of acquisition. Quite different picture is visualized in English Medium Schools. In EMS all the skills are given equal importance such as - accuracy pronunciation \& Fluency. But like BMs native speaker like accent are not focused here as students are already well built up in English communicative environment.

3. However most of the students of Bangla Medium Schools are evaluated by telling synonyms and memorization based writings. They are not encouraged to express their creativity. But in EMS students are encouraged and given chance to illustrate new sentences by their own. They are asked to make group discussion and present their own views on a given topic.

4. Though, both the students of Bangla and English Medium schools are well informed about the dire need of evaluation in their in their learning process, the BM students still limit their insights on assessment only in learning selected items of a language. In BMS grammatical rules are overtly exercised for L2 speaking learning. 
The conducive atmosphere inside and outside the classrooms are very rare. But Ems are stepping forward in this regard and their assessment system is well equipped. They do not need to test students' speaking skill separately as they are provided with realistic communicative environment. Therefore, their purpose of assessment is to cope up with global communication.

5. In English Medium School, students are assessed formatively so they can monitor their learning points. They are informed weekly or monthly what to retain or reject whereas very opposite picture is encountered in Bangla Medium School. In BM, students are assessed once or twice in a year that is even done to help them promote the next grade, not to aid their speaking skill. Conclusively, this setting proves formative assessment is more effective than that of summative one.

6. Considering all the findings, it can be highlighted that the biggest loophole of implementing inclusive assessment systems in BMs is their education system. The objective of the curriculum never provokes any force to put focus on assessment.

\section{Conclusion:-}

The study has shown explicitly the need of evaluation to take lead in developing L2 speaking. Instructors, practitioners, policy makers and few other stakeholders have distinctive role to ensure effective assessment system in any institution. Though a particular setting was emphasized to collect the data for this empirical research, the results can be generalized to any number of populations who are learning ESL speaking. Also, there is a concern about the reliability of the result as the participants were unconsciously providing tentative information. Few of them weren't much attentive while marking the options of questionnaire. On top of that, they assumed this was test given to them and they remained scared until further explanation provided. However, notably the consequence of having healthy testing system can enlighten teaching and learning of L2 speaking in NCTB schools in Bangladesh.

The followings can help promote assessment system in NCTB schools in Bangladesh:

1. Assessment of ESL speaking needs to be included in NCTB curriculum. Speaking competency of Bangla Medium learners must be evaluated like English Medium's ones in semester exams.

2. Institutions should focus on formative assessment. It guides learners immediately what to do in order to improve their speaking skill.

3. Hands on supports from institution can facilitate the application of assessment.

4. The teachers, instructors and any other related community should prepare learners to be adaptive with regular assessment. If learners aren't emotionally safe and secured, they might be afraid of being examined.

5. Before judging the performance of a learner, a congenial L2 speaking environment needs to be ensured. An instructor should carry proper teaching aids to ensure better performance of learners. Different teaching aids can help generate a perfect situation for teaching and learning L2 speaking.

6. Finally, trained instructors, who know much about assessment, can do the best to execute and formulate the appropriate assessing criteria for his or her class.

\section{Abbreviation Lists:}

BM: Bangla Medium, EM: English Medium, BMs: Bangla Medium Schools, Ems: English Medium Schools. NCTB: National Curriculum and Textbook Board, ESL: English as a Second Language. L2: Second Language.

\section{References:-}

1. Ahmad, N. (2011). Analyzing the Spoken English Needs in Pakistani Academic Legal Settings. Pakistan. Journal of Social Sciences (PJSS), 31(2): 449-469.

2. Akiyama, T. (2003). Assessing speaking in Japanese junior high schools: Issues for the senior high school entrance examinations. Shiken. JALT Testing \& Evaluation SIG Newsletter, 7(2): 2-11.

3. Alam, M. (2012). Assessment of Oral Skills Development among the Students of Master in Education in the Public Sector Universities of Punjab. University of Sargodha Sargodha: Master of Philosophy.

4. Ali, A., Tariq, RH., \& Topping, KJ. (2012). Perspectives of academic activities in universities in Pakistan. Journal of Further and Higher Education, 1-28.

5. Assessment. (1995). In Cambridge $\quad$ Dictionary. $\quad$ Retrieved from https://dictionary.cambridge.org/dictionary/english/assess?q=Assessment

6. Barman, B., Sultana, Z., \& Basu, B. L. (2006). ELT Theory and Practice. Dhaka: Friends' Book Corner

7. Bashir, M. (2011). Factor Effecting Students' English Speaking Skill. British Journal of Arts \& Social Sciences, 2(1):34-50. 
8. Bilal, HA., Rehman, A., Rashid, A., Adnan, R., \& Abbas, M .(2013). Problems in Speaking English with L2 Learners of Rural Area Schools of Pakistan. Language in India, 13(10):1220-1235.

9. Black, P., \& Wiliam, D. (1998). Assessment and classroom learning. Educational Assessment: Principles, Policy and Practice, 5(1), 7-74.

10. Boud, D.,\& Falchikov, N. (2006): Aligning assessment with long-term learning. Assessment \& Evaluation in Higher Education, 31(4):399-413. 10.1080/02602930600679050

11. Bruton, A. (2009). The Vocabulary Knowledge Scale: A Critical Analysis. Language Assessment Quarterly, 6(4):288-297. 10.1080/15434300902801909

12. Crooks, T. (1988). The impact of classroom evaluation practices on students. Review of Educational Research, 58(4):438-481. 10.3102/00346543058004438

13. Dhindsa, H., Omar, K., \& Waldrip, B. (2007, August 1). Upper Secondary Bruneian Science Students' Perceptions of Assessment. International Journal of Science Education, 29(10), 1281-1280.

14. Gattullo, F. (2000). Formative assessment in ELT primary (elementary) classrooms: an Italian case study. Language Testing, 17 (2), 278-288.

15. Great School Partnership. (2014). The glossary of Education reform. Retrieved from https://www.edglossary.org/high-stakes-testing/

16. Harris, D. P. (1969). Testing English as a Second Language. New York, NY: McGraw-Hill Book Co.

17. Heaton, J. B. (1989). Writing English Language Tests. UK: Longman Publishers. ISBN: 0-582-aa00237-0

18. Heywood , J. (1989). Assessment in Higher Education. New York: John Wiley \& Sons.

19. Huang, S. (2012). Pushing Learners to Work Through Tests \& Marks: Motivating or Demotivating? A Case in a Taiwanese University. Language Assessment Quarterly, 9: 60-77. doi:10.1080/15434303.2010.510898

20. Hughes, A. (1989) Testing for Language Teachers. Pp. 5-50. United Kingdom, UK: Cambridge University Press.

21. Huxham, M., Campbell, F., \& Westwood, J. (2012). Oral versus written assessments: a test of student performance \& attitudes. Assessment \& Evaluation in Higher Education, 37(1):125136.10.1080/02602938.2010.515012

22. Knight, B. (1992). Assessing speaking skills: a workshop for teacher development. ELT Journal , 46(3): 294302. 10.1093/elt/46.3.2943.

23. Lee, Y. (2007). The Multimedia Assisted Test of English Speaking: The SOPI Approach. Language Assessment Quarterly, 4(4):352-366. 10.1080/15434300701533661.

24. Newble, DI., Jaeger, K. (1983). The effects of assessment \& examinations on the learning of medical students. Medical Education, 20: 162-175.

25. Sánchez, L. (2006). Bilingualism/second-language research and the assessment of oral proficiency in minority bilingual children. Language Assessment Quarterly: An International Journal, 3(2):117-149. 10.1207/s15434311laq0302_3.

Appendix 1:-

The Role of Assessments in Developing L2 Speaking: A Comparative Study between the Young Learners of Bangla and English Medium Education syestem in Bangladesh.

Data collected by this survey questionnaire will be used to complete an academic research paper and no information will be disclosed for any harmful acts.

Name: Institute

\section{Class:................. Age............... Gender: Male/Female}

Direction: The following questions are multiple choice types. Students are requested to put tick mark $(\checkmark)$ on right the option.

1. How many times is your L2 speaking assessed in a year?
(a) 2
(b) less than 2
(c) 4
(d) more than 4

2. Which of the following oral test are you given?
(a) Weekly short test
(b) Monthly big test
(c) Quarterly big test
(d) Half/ annually

3. Which technique is applied to identify the ability of learners of using vocabulary?
(a) Memorization
(b) Making sentence with new word
(c) Writing a story with new words
(d) Telling synonym of each new word.

4. Which specific area of $\mathrm{L} 2$ speaking skill is frequently focused in L2 classroom?
(a) Accuracy
(b) Fluency
(c) Pronunciation
(d) Accent 
5. How far has evaluation raised a comprehensive impact on your L2 Speaking?
(a) Wider
(b) Very Little
(c) No Impact
(d) Medium

6. Why is assessment important?
(a) To improve pronunciation
(b) To become more fluent speaker
(c) To improve English test score
(d) To expand vocabulary

7. Is improvement of a real or realistic communication in $\mathrm{L} 2$ is impossible without integrating assessment in learning process?
(a) Agree
(b) Strongly Agree
(c) Disagree
(d) Strongly Disagree

Direction: The following questions are order of frequency. Your assistance in completing the following questions is greatly appreciated.

\begin{tabular}{|l|l|l|l|l|}
\hline Sl no. & Question & Always & Sometimes & Often \\
\hline 08. & $\begin{array}{l}\text { Do your instructors give any sudden test for } \\
\text { assessing L2 speaking? }\end{array}$ & & Never \\
\hline 09. & $\begin{array}{l}\text { Do you get immediate feedback from your } \\
\text { teacher? }\end{array}$ & & & \\
\hline
\end{tabular}

\section{Appendix-3}

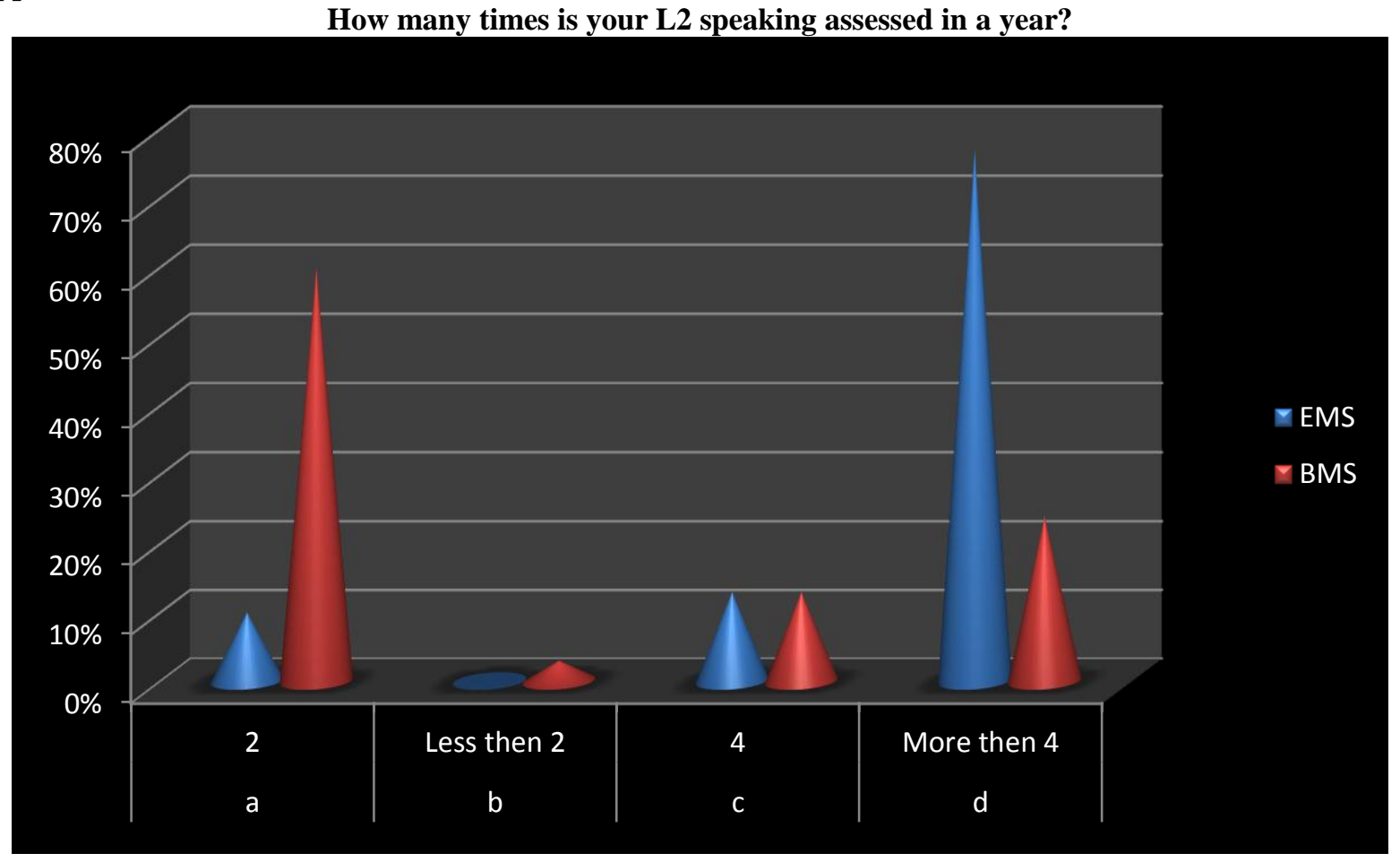


Which of the following oral test are you given?

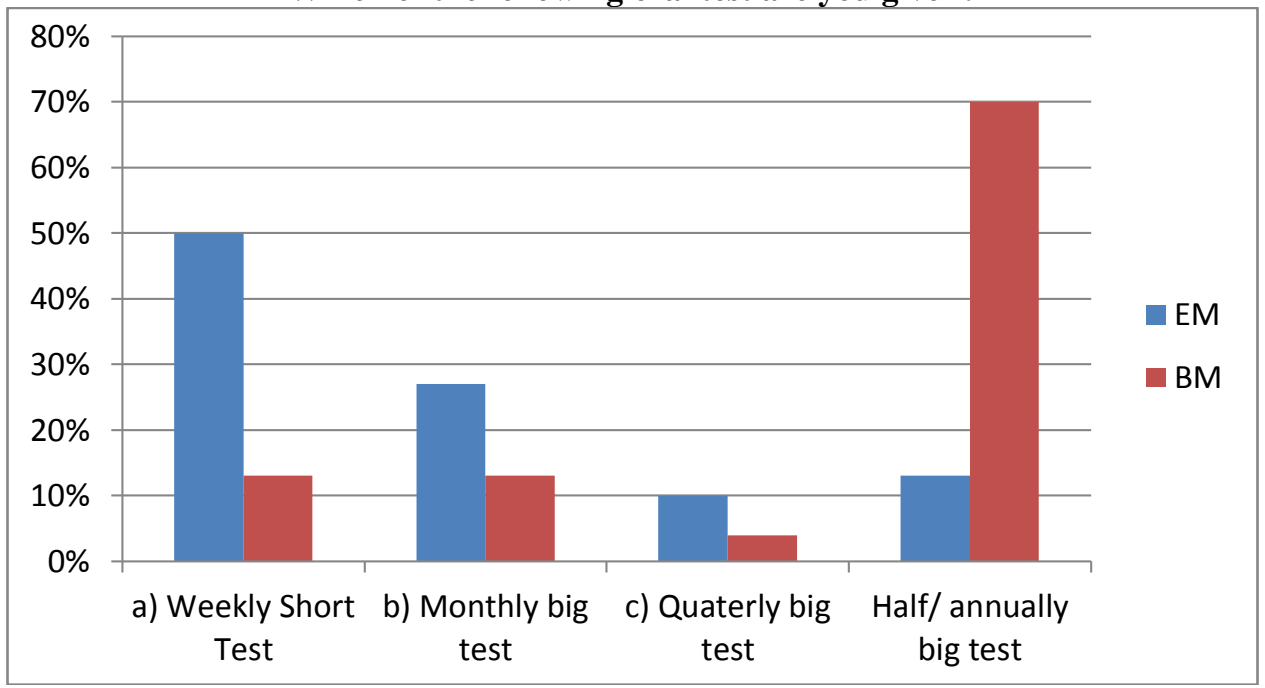

Which approach is applied to identify the ability of learners of using vocabulary?

\section{EM}

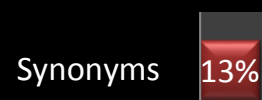

Story with new words

Sentence with new words

Memorisation

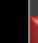

3

$3 \%$
$24 \%$

$60 \%$
Synonyms

BM
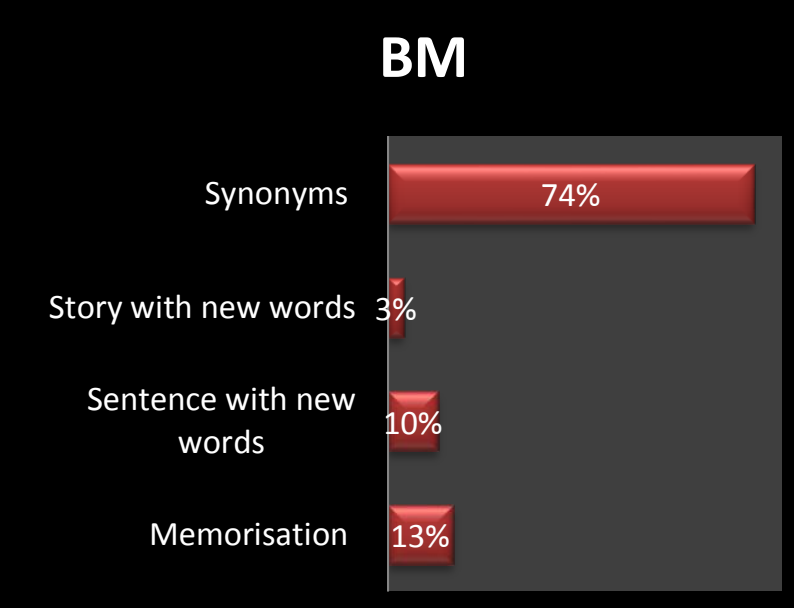

Which specific area of L2 speaking skill is frequently focused in L2 classroom?
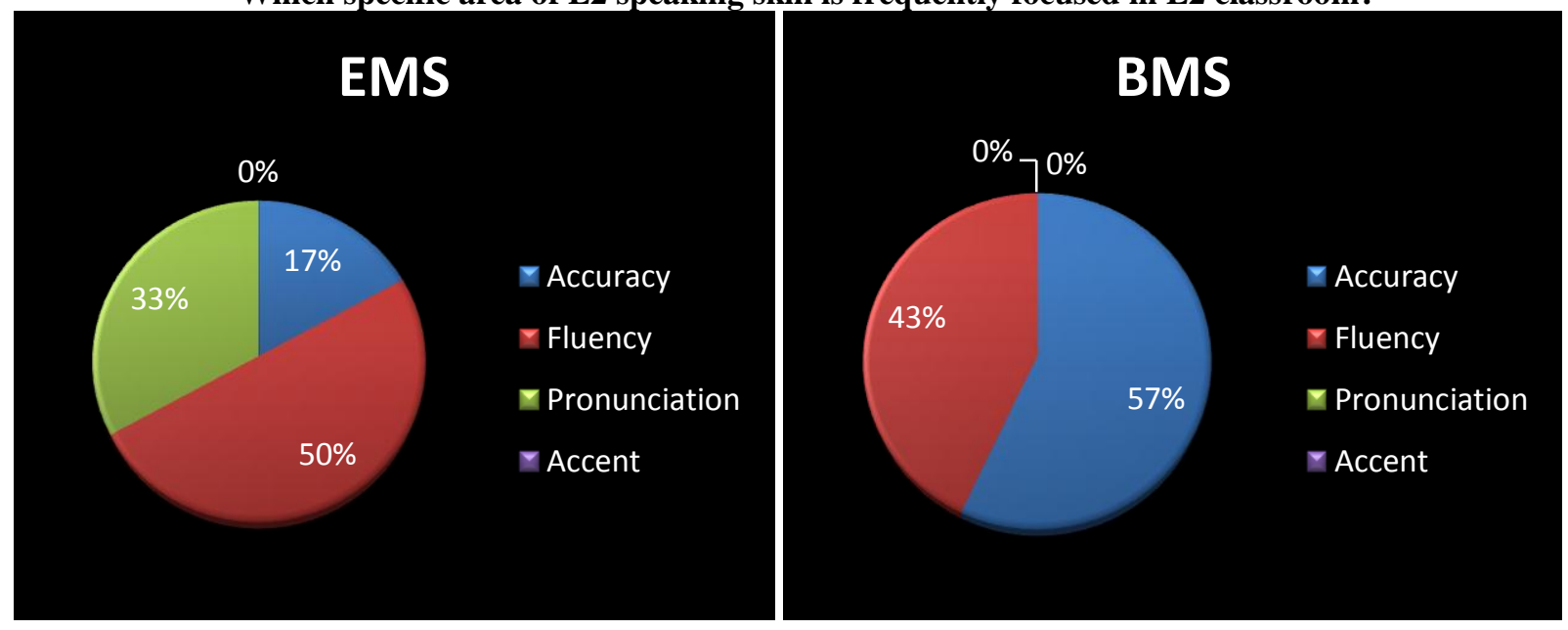
How far has evaluation raised a comprehensive impact on your L2 Speaking?

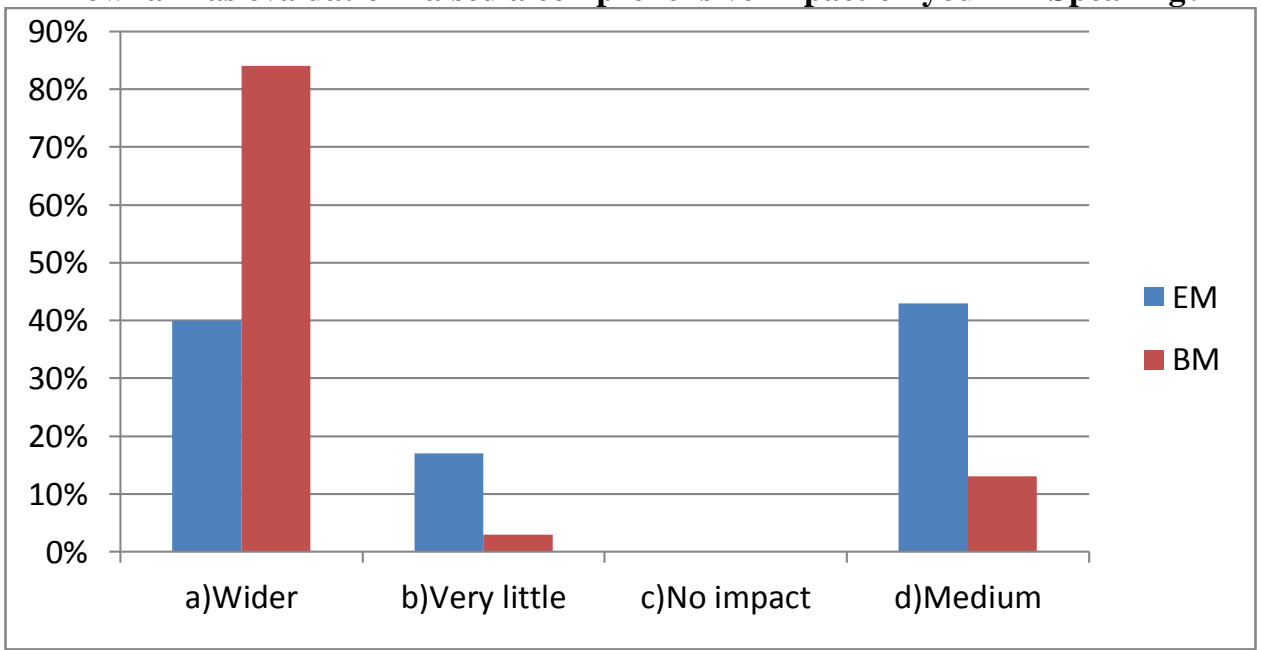

Why is assessment important?
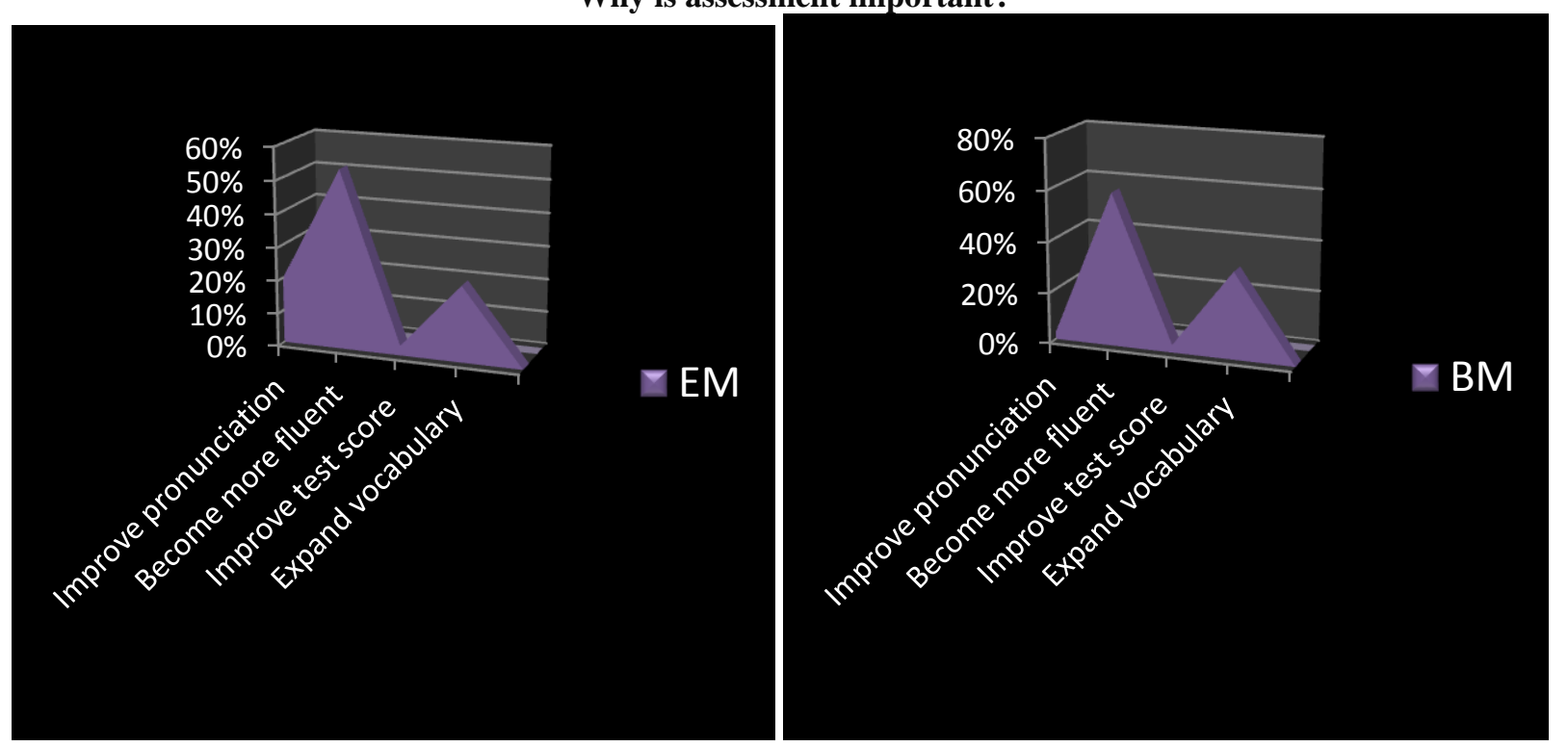

Is improvement of a real or realistic communication in $\mathbf{L} 2$ is impossible without integrating assessment in learning process?

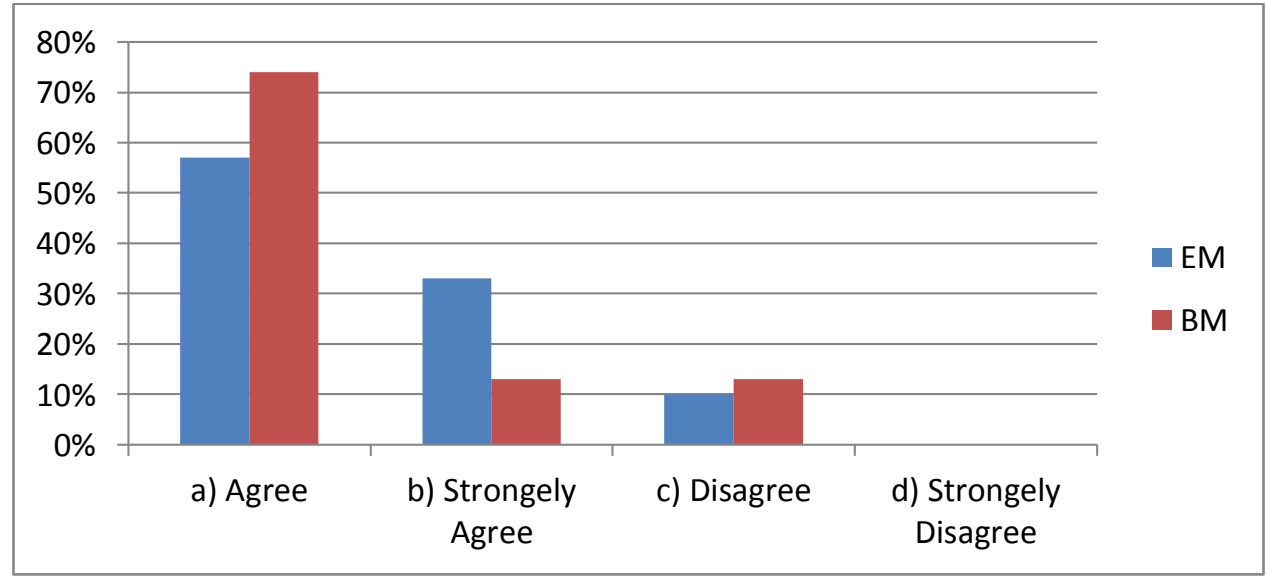


Do your instructors give any sudden test for assessing L2 speaking?

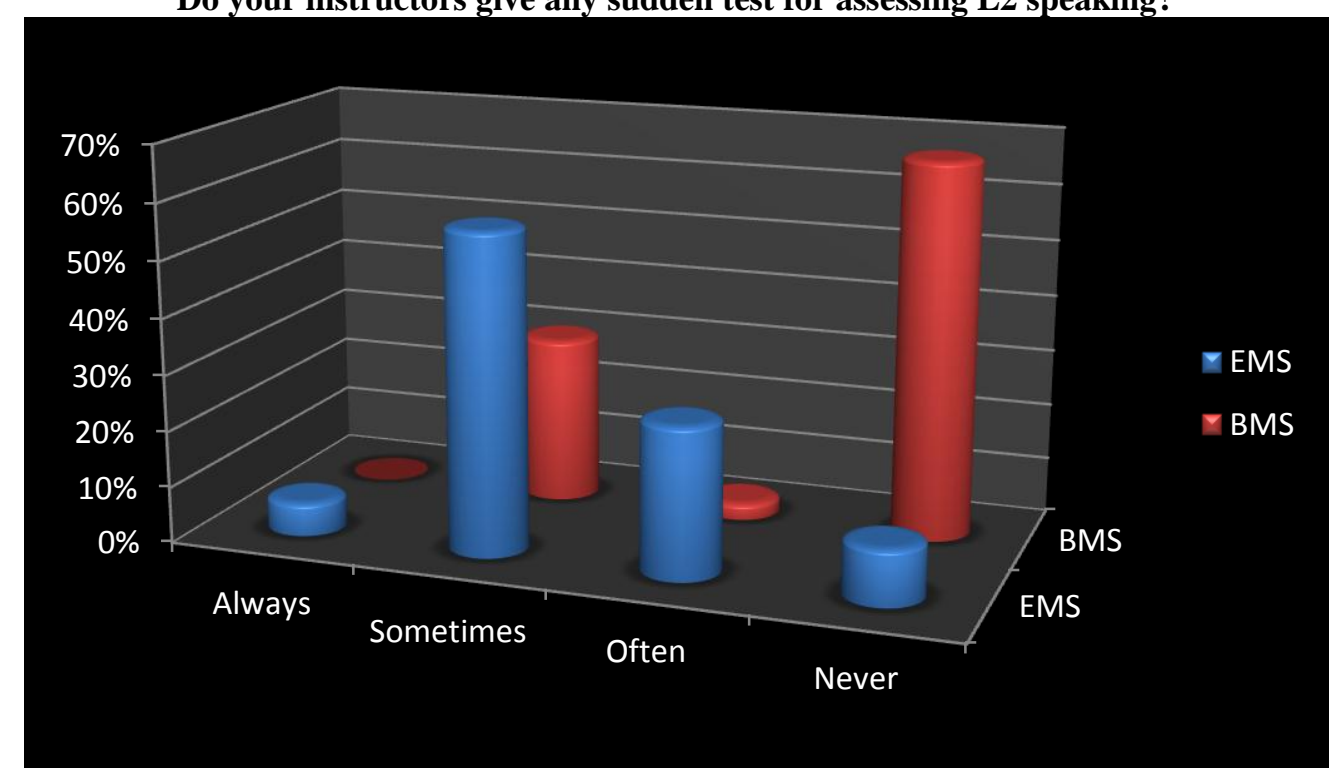

Do you get immediate feedback from your teacher?

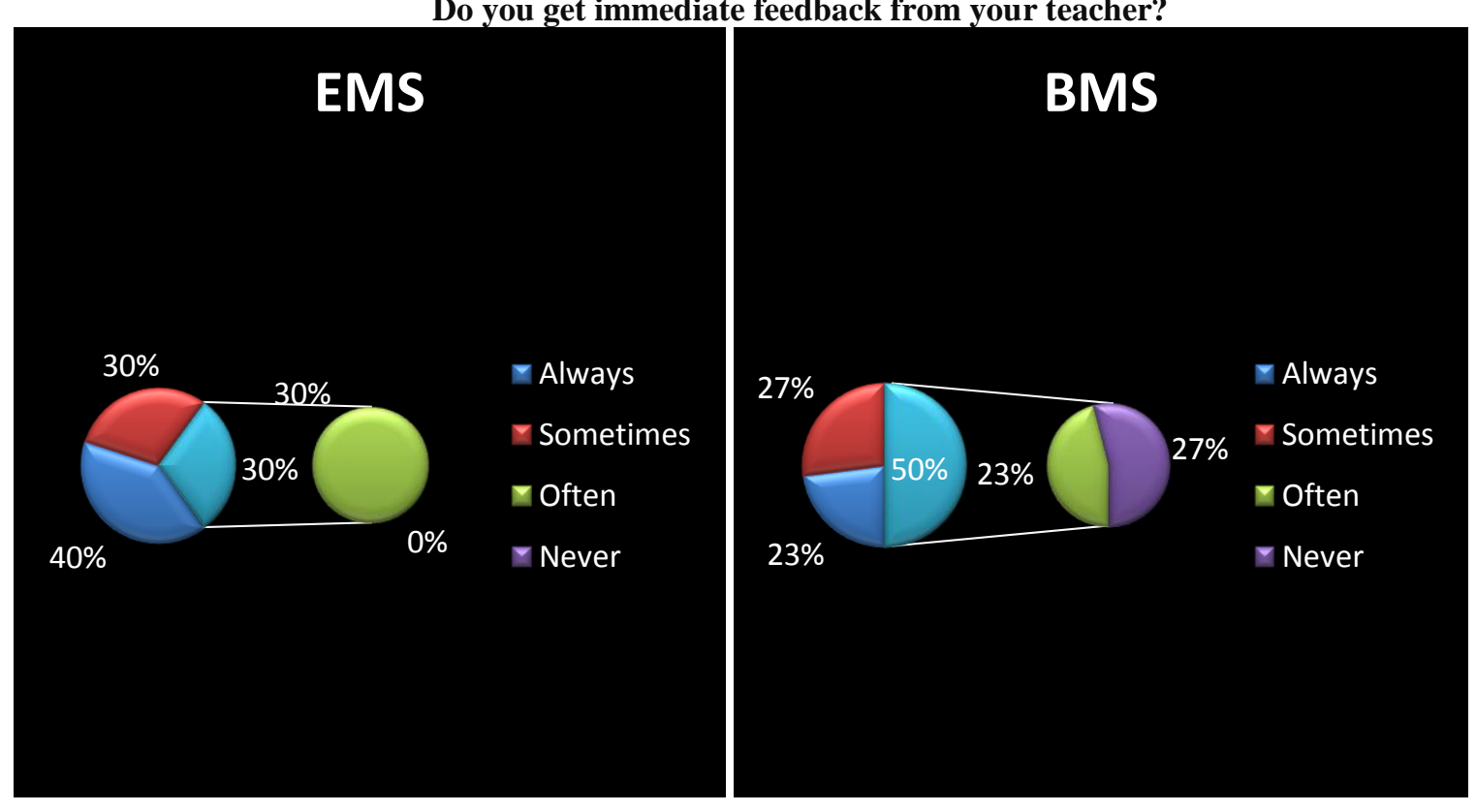


Appendix-2

Tabulations Sheet of Raw Data from participants

\begin{tabular}{|c|c|c|c|c|c|c|c|}
\hline \multirow[t]{2}{*}{$\begin{array}{l}\text { QUESTION } \\
\text { S }\end{array}$} & \multirow[t]{2}{*}{$\begin{array}{lr}\text { OPTIONS } & \text { OF } \\
\text { EACH QUESTION }\end{array}$} & \multicolumn{2}{|c|}{$\begin{array}{l}\text { NUMBER OF } \\
\text { STUDENTS } \\
\text { SEPERATELY }\end{array}$} & \multicolumn{2}{|c|}{$\begin{array}{l}\text { PERCENTAGE } \\
\text { SEPERATELY }\end{array}$} & \multirow{2}{*}{$\begin{array}{l}\text { NUMBER } \\
\text { OF } \\
\text { STUDENT } \\
\text { S } \\
\text { EM\&BM } \\
\end{array}$} & \multirow{2}{*}{$\begin{array}{l}\text { PERCENTANG } \\
\text { E FOR BOTH } \\
\text { EM \&BM } \\
\text { EM\&BM }\end{array}$} \\
\hline & & EM & BM & EM & BM & & \\
\hline \multirow[t]{5}{*}{ Q.1 } & a)2 & 3 & 18 & $10 \%$ & $60 \%$ & 21 & $35 \%$ \\
\hline & b)Less than 2 & 0 & 1 & $0 \%$ & $3 \%$ & 1 & $2 \%$ \\
\hline & c)4 & 4 & 4 & $13 \%$ & $13 \%$ & 8 & $13 \%$ \\
\hline & d)More than 4 & 23 & 7 & $77 \%$ & $24 \%$ & 30 & $50 \%$ \\
\hline & & $\begin{array}{l}\text { N.S }=3 \\
\text { 0 }\end{array}$ & $\begin{array}{l}\text { N.S }=3 \\
\text { 0 }\end{array}$ & $\begin{array}{l}T= \\
100 \%\end{array}$ & $\begin{array}{l}T=100 \\
\%\end{array}$ & N.S.E $=60$ & $\mathrm{~T}=100 \%$ \\
\hline \multirow[t]{6}{*}{ Q.2 } & a) Weekly short test & 15 & 4 & $50 \%$ & $13 \%$ & 19 & $32 \%$ \\
\hline & b) Monthly big test & 8 & 4 & $27 \%$ & $13 \%$ & 12 & $20 \%$ \\
\hline & c) Quarterly big test & 3 & 1 & $10 \%$ & $4 \%$ & 4 & $6 \%$ \\
\hline & d)Half/Annually & 4 & 21 & $13 \%$ & $70 \%$ & 25 & $42 \%$ \\
\hline & & $\begin{array}{l}\text { N.S=3 } \\
\text { 0 }\end{array}$ & $\begin{array}{l}\text { N.S=3 } \\
\text { 0 }\end{array}$ & $\begin{array}{l}T= \\
100 \%\end{array}$ & $\begin{array}{l}\mathrm{T}=100 \\
\%\end{array}$ & $\mathrm{~T} . \mathrm{S}=60$ & $\mathrm{~T}=100 \%$ \\
\hline & & $\begin{array}{l}\text { N.S=3 } \\
\text { 0 }\end{array}$ & $\begin{array}{l}\text { N.S }=3 \\
0\end{array}$ & $\begin{array}{l}\mathrm{T}= \\
100 \%\end{array}$ & $\begin{array}{l}\mathrm{T}=100 \\
\%\end{array}$ & $\mathrm{~T} . \mathrm{S}=60$ & $\mathrm{~T}=100 \%$ \\
\hline \multirow[t]{5}{*}{ Q.3 } & a)Memorization & 1 & 4 & $3 \%$ & $13 \%$ & 5 & $8 \%$ \\
\hline & $\begin{array}{l}\text { b)Making sentence } \\
\text { with new words }\end{array}$ & 18 & 3 & $60 \%$ & $10 \%$ & 21 & $35 \%$ \\
\hline & $\begin{array}{l}\text { c)Writing a story } \\
\text { with new words }\end{array}$ & 7 & 1 & $24 \%$ & $3 \%$ & 8 & $14 \%$ \\
\hline & $\begin{array}{l}\text { d)Telling synonyms } \\
\text { of each words }\end{array}$ & 4 & 22 & $13 \%$ & $74 \%$ & 26 & $43 \%$ \\
\hline & & $\begin{array}{l}\text { N.S }=\mathbf{3} \\
\text { 0 }\end{array}$ & $\begin{array}{l}\text { N.S }=\mathbf{3} \\
\text { 0 }\end{array}$ & $\begin{array}{l}T= \\
100 \%\end{array}$ & $\begin{array}{l}\mathrm{T}=100 \\
\%\end{array}$ & $T . S=60$ & $\mathrm{~T}=100 \%$ \\
\hline \multirow[t]{5}{*}{ Q.4 } & a) Accuracy & 5 & 17 & $17 \%$ & $57 \%$ & 22 & $36 \%$ \\
\hline & b) Fluency & 15 & 13 & $50 \%$ & $43 \%$ & 28 & $46 \%$ \\
\hline & c) Pronunciation & 10 & $\mathbf{0}$ & $33 \%$ & $0 \%$ & $\mathbf{1 0}$ & $18 \%$ \\
\hline & d) Accent & $\mathbf{0}$ & $\mathbf{0}$ & $0 \%$ & $0 \%$ & 0 & $\mathbf{0 \%}$ \\
\hline & & $\begin{array}{l}\text { N.S }=3 \\
0\end{array}$ & $\begin{array}{l}\text { N.S=3 } \\
\mathbf{0}\end{array}$ & $\begin{array}{l}\mathrm{T}=100 \\
\%\end{array}$ & $\begin{array}{l}\mathrm{T}=100 \\
\%\end{array}$ & $T . S=60$ & $\mathrm{~T}=100 \%$ \\
\hline \multirow[t]{5}{*}{ Q.5 } & a)Wider & 12 & 25 & $40 \%$ & $84 \%$ & 37 & $62 \%$ \\
\hline & b) Very little & 5 & 1 & $17 \%$ & $3 \%$ & 6 & $10 \%$ \\
\hline & c)No impact & 0 & 0 & $0 \%$ & $0 \%$ & 0 & $0 \%$ \\
\hline & d)Medium & 13 & 4 & $43 \%$ & $13 \%$ & 17 & $28 \%$ \\
\hline & & $\begin{array}{l}\text { N.S=3 } \\
\text { 0 }\end{array}$ & $\begin{array}{l}\text { N.S }=3 \\
\text { 0 }\end{array}$ & $\begin{array}{l}T= \\
100 \%\end{array}$ & $\begin{array}{l}T=100 \\
\%\end{array}$ & $T . S=60$ & $\mathrm{~T}=100 \%$ \\
\hline \multirow[t]{5}{*}{ Q.6 } & $\begin{array}{l}\text { a)To improve } \\
\text { pronunciation }\end{array}$ & 6 & 1 & $20 \%$ & $3 \%$ & 7 & $12 \%$ \\
\hline & $\begin{array}{l}\text { b)To become more } \\
\text { fluent speaker }\end{array}$ & 16 & 18 & $54 \%$ & $60 \%$ & 34 & $57 \%$ \\
\hline & $\begin{array}{l}\text { c)To improve } \\
\text { English test score }\end{array}$ & 1 & 1 & $3 \%$ & $3 \%$ & 2 & $3 \%$ \\
\hline & $\begin{array}{ll}\text { d)To } & \text { expand } \\
\text { vocabulary } & \end{array}$ & 7 & 10 & $23 \%$ & $34 \%$ & 17 & $28 \%$ \\
\hline & & $\begin{array}{l}\text { N.S=3 } \\
\text { 0 }\end{array}$ & $\begin{array}{l}\text { N.S }=3 \\
0\end{array}$ & $\begin{array}{l}\mathrm{T}= \\
100 \%\end{array}$ & $\begin{array}{l}\mathrm{T}=100 \\
\%\end{array}$ & $T . S=60$ & $\mathrm{~T}=100 \%$ \\
\hline Q-7 & a) agree & 17 & 22 & $57 \%$ & $74 \%$ & 39 & $65 \%$ \\
\hline
\end{tabular}




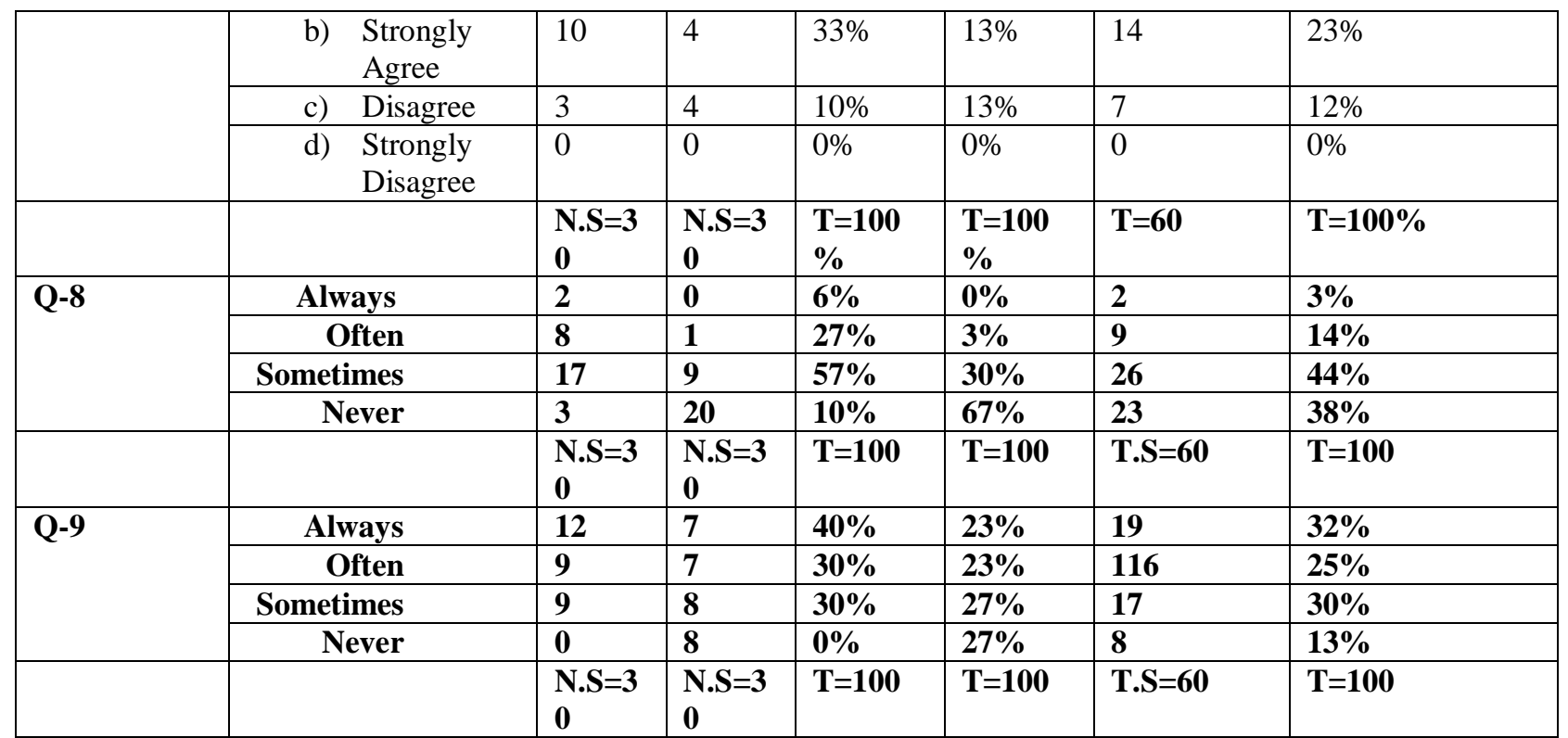

